\title{
Straffrätten på 2020-talet - från Cesare Beccarias Om brott och straff (1764) till en allt mer internationell och europeisk straffrätt ${ }^{1}$
}

\author{
Professor Raimo Lahti ${ }^{2}$
}

\begin{abstract}
This article provides a fragmentary overview of the developments of criminal law and criminal policy in Finland during the last 150 years. It reflects the author's experiences as a criminal scientist and an expert in drafting criminal legislation over 48 years. This review uses the conclusions from Cesare Beccaria's classic, 250-year-old book as its starting point: that a punishment may not be an act of violence; that it should be public, immediate, necessary, as minimal as the case allows, proportional to the crime and determined by the law.

The Finnish Penal Code of 1889 was originally thoroughly permeated by both the principles and the spirit of the Classical School of penal law wherein punishment was primarily regarded as retribution for the offence and the penal system was therefore tolerably harmonious with the demands of general deterrence. Later on, the influence of the sociological school of penal law, which focused on the offender and individualized criminal sanctions, led to partial reforms of the penal system, e.g., enactment of the Conditional Sentences Act of 1918, the Dangerous Recidivists Act of 1932 and Young Offenders Act of 1940.

The total reform of the Penal Code between 1972 and 2003 aimed to create a more rational penal system, i.e. one designed for efficient, just and humane criminal justice. An ambitious attempt was made in as uniform and systematic a way as possible to assess the goals, interests and values that the new Criminal Code should promote and protect. The existence of the criminal justice system was defended on utilitarian grounds. The structure and operation of the penal system cannot, however, be founded solely on the basis of utility. The criteria of justice and humaneness must also be applied. The penal system must be rational in regard to both its goals (utility) and its values (justice; humaneness).

Developments since the 1990s are characterized by the influence of human rights and basic rights on both criminal and procedural law, as well as by the effects of the internationalization and Europeanization of the criminal justice system. These latter-mentioned tendencies have resulted in the diversification of some parts of the criminal law and an increased pluralism of general legal doc-
\end{abstract}


trines. Criminal scientists in Finland and the rest of Scandinavia should strive more actively to influence both European and global criminal policy in the direction of the 'Nordic model' - which emphasizes crime prevention, applies specific rational criteria such as legitimacy and humaneness, and plays down repression in criminal sanctions. ${ }^{*}$

\section{Inledning}

I detta framförande skapar jag en överblick av den straffrättsliga och straffrättsvetenskapliga utvecklingen genom att spåra de rättsideologiska inriktningar som påverkat den. Jag belyser mitt framförande framförallt med mina egna erfarenheter som forskare i straffrätt och sakkunnig som deltagit i lagberedning.

Fastän uppmärksamheten i huvudsak riktar sig mot utvecklingen i Finlands straffrätt, finns det skäl att poängtera att de ideologier som finns i bakgrunden av tradition har följt internationella trender. Med presentationens rubrik vill jag ändå föra fram att den finska straffrättens bundenhet till den internationella, och särskilt den europeiska, utvecklingen har blivit starkare under de senaste årtiondena.

I början av denna överblick bedömer jag betydelsen av Cesare Beccarias klassiska verk "Dei delitti e delle pene" (Om brott och straff, 1764) från 250 år tillbaka. Jag avslutar min presentation med en framtidsbild av 2020-talets straffrätt.

Den person som mest påverkat mitt straffrättsliga tänkande är min lärare Inkeri Anttila, som gick bort år 2013. ${ }^{4}$ De stimulanser för forskararbete hon frambringat kan uttryckas med nyckelbegreppen mångvetenskaplighet, internationalism och effektfullhet (dvs. förbindelsen mellan teori och praktik).

Av dessa begrepp har mångvetenskaplighet för mig inneburit att omfatta en vidsträckt uppfattning om straffrätts- eller kriminalvetenskapen, varvid den rättsliga forskningen bör förenas med inslag och synvinklar från den empiriska samhällsvetenskapliga och politiska forskningen. Följaktligen bör även den straffrättsliga undervisningen och forskningen förbindas till kriminologi och kriminalpolitik. Mångvetenskap kan framkomma även genom överskridande av gränser rättsområden emellan. För mig själv har medicin- och biorätten, för vilken jag var ansvarslärare med tjänsten som bisyssla under åren 1997-2011, inneburit ett berikande perspektiv på rättssystemet.

* Title in English: Criminal law in the 2020s: From Cesare Beccaria's "On Crimes and Punishments" (1764) to the internationalization and Europeanization of criminal justice 
Internationalism har för mig inneburit att delta i vetenskapliga organisationers kongresser och andra tillställningar inom mina egna vetenskapsområden, gränsöverskridande kontakt med andra forskare och forskningssamarbete. Det har också inneburit att de rättskällor och influenser som beaktas i forskningen har internationaliserats samt att delta i att åstadkomma normer och standarder som är betydelsefulla för den internationella kriminalpolitiken.

Växelverkan mellan teorin och praktiken har för min del förverkligats genom mitt deltagande som sakkunnig i lagberedning från och med år 1967, mest anmärkningsvärt i ledningsgruppen för strafflagsprojektet angående strafflagstiftningens totalrevision, som löd under justitieministeriet, under hela dess verksamhetstid 1980-1999. Då en strafflagstiftning sällan totalrevideras - kanske en gång per århundrade -, har det varit en unik utsiktsplats för en forskare i straffrätt att delta i den.

Det är nostalgiskt att hålla avskedsföreläsning i juridiska fakultetens hembyggnad Porthania. Här påbörjade jag mina juridiska studier för 50 år sedan och Porthania har varit min arbetsplats som lärare och forskare i straffrätt i 48 år, om också jag arbetade fem år av den tiden i Åbo universitets tjänst. Jag har särskilt tyckt om undervisning av seminarietyp och personlig arbetshandledning. ${ }^{5}$ Under mina 40 år som professor har jag handlett ungefär femhundra avhandlingar som slutförts och vilka varit minst på magister- eller fortsättningsstudienivå, bland dessa 25 doktorsavhandlingar.

\section{Om Cesare Beccarias "Om brott och straff" (1764) och verkets betydelse} Cesare Beccarias verk Om brott och straff har ansetts vara ett av upplysningens mest betydande verk, som bottnar sig i utilitaristisk filosofi alltså i nyttotänkande, vilket skrivits i jämlikhetens, frihetens och toleransens anda. Beccaria motsatte sig dödsstraff och andra grymma straff. Verket översattes snabbt till de största europeiska språken och många av Europas härskare började förnya sina länders strafflagstiftningar influerade av verket.

Den svenska översättningen (1770) var bland de första översättningarna av Beccarias verk. Sveriges regent Gustav III blev inspirerad av verket för sina åtgärder att mildra straffsystemet och avskaffa tortyren. Beccarias samtida Matthias Calonius, karaktäriserad som den finska straffrättsvetenskapens fader, rekommenderade verket, fastän han konstaterade att det gick för långt i sin humana filosofi. ${ }^{6}$

Enligt en uppskattning påverkade upplysningsfilosofin det straffrättsliga tänkandet särskilt beträffande den rationalism som upplysningen betonade, varvid humaniseringen av straffrättssystemet i jämförelse blir sekundärt. ${ }^{7}$ Det är intres- 
sant att jämföra de för upplysningen karakteristiska begreppen rationalism och humanism med de krav på en rationell och human kriminalpolitik som hos oss lyfts fram två århundraden senare. Till de senaste årtiondenas krav återkommer jag nedan. Jag citerar här den dogm som formuleras i slutsatserna till Beccarias verk, eftersom den fortfarande har ett budskap som är mycket gångbart:

"... för att varje straff inte skall innebära våld som en eller flera utövar mot en enskild medborgare bör det obetingat vara offentligt, omedelbart, nödvändigt, det minsta möjliga under de givna omständigheterna, avpassat efter brottet och dikterat av lagen".

\section{Bestraffningsideologin i 1889 års strafflag och dess senare ändringar}

Under lantdagarna åren 1863-64 godkändes grunderna för den nya strafflagen för efterföljande beredning som varade i ett kvartssekel. Den kejserliga propositionen om dessa grunder innefattade ett detaljerat förslag om de straff som skulle tas i bruk och ur bruk i och med den nya lagen. Propositionens viktigaste utdelning var alltså ur dagens perspektiv en progressiv programförklaring för ett omfattande revisionsarbete av det straffrättsliga påföljdssystemet. Denna proposition, som i sina huvuddrag fick ständernas godkännande, innehöll förslag om avskaffande av dödsstraffet samt frånträdande av användningen av kropps- och skamstraff och landsförvisning. Straffsystemets grundstomme skulle bestå av tukthus- och fängelsestraff samt böter. Verkställigheten av frihetsstraffen skulle ordnas enligt principerna för en progressiv behandling av fångar, varvid villkorlig frigivning skulle utgöra en del av ett sådant progressivt system. ${ }^{9}$

I lagutskottets betänkande från år 1867 finns ett principuttalande som fortfarande är beaktansvärt: "Kriminalrättens historie lärer att bestraffningsmedlen under en fortskridande civilisation söka en mildare form samt att den allmänna kulturens framåtskridande beledsagas af enahanda progression i uppfattningen af rättsvisans fordringar och af de medlen, hon för sitt förverkligande måste begagna." 10 Det är intressant att jämföra detta uttalande med till exempel Tapio Lappi-Seppäläs färska forskningsresultat: i grunden förklaras Nordens kriminalpolitik och därmed bland annat dess relativt låga repressionsnivå (samt rätt låga fångtal) av de för välfärdsstaten typiska samhälleliga och kulturella särdragen, vilka skapar förutsättningar för medborgarnas tillit och upplevd legitimitet gentemot myndigheters och rättsväsendets verksamhet. ${ }^{11}$

Då de målsättningar som sedermera ställts upp för straffsystemet i 1889 års strafflag bedöms märker man att straffsystemet inte enbart förutsattes uppfylla kraven på rättvisa som är förenliga med idén om försoning, att straffet skulle stå i proportion till gärningen. En strävan efter avskräckning, som antyder en general- 
preventiv verkan, och till förbättring karaktäristiskt för den specialpreventiva verkan, ställdes också upp för systemet. Man ville även göra straffsystemet mera humant än tidigare.

I 1889 års strafflag, drivet av lagens fader Jaakko Forsman, kvarhölls den s.k. klassiska straffrättsskolans idé om försoning som primära bedömningsgrund för straffsystemet, men även målsättningen om förbättring av gärningsmannen uttrycktes, framför allt i sättet som verkställigheten av frihetsstraffen ordnades. Dödsstraff och förlust av medborgerligt förtroende kvarhölls i straffsystemet, tvärtemot programdeklarationen i 1863-64 års lantdagar; de avskaffades som påföljdsformer slutgiltigt först under det sena 1960-talet och det tidiga 1970-talet. Visserligen verkställdes det sista fredstida dödsstraffet år 1825.

Under de årtionden som följde ikraftträdandet av 1889 års strafflagstiftning ändrade det straffrättsliga tänkandet till följd av den s.k. sociologiska (moderna) skolans inverkan. Allan Serlachius, som på uppdrag av justitieministeriet beredde strafflagsförslaget år 1920, var en fast anhängare av skolan. Från och med början av 1910-talet gjordes det ändringar i straffsystemet, enligt vilka man vid valet av påföljdsart mera än tidigare skulle beakta den dömdes person och specialpreventiva syften (återanpassning i samhället eller ofarliggörande). Typiska exempel på hur detta tankesätt återspeglas är lagrevisionerna gällande det villkorliga straffet (1918), internering i tvångsinrättning (1932, 1953), återfall i brott (1939) och unga förbrytare (1940). En internationellt uppmärksammad reform som motiverades med kravet på rättvisa var ibruktagandet av dagsbotssystemet år 1921, vilket beaktade förmögenhetsställningen av dem som skulle straffas. ${ }^{12}$

\section{Tanken bakom strafflagstiftningens totalrevision åren 1972-2003: mot en rationell och human kriminalpolitik}

Inkeri Anttila publicerade år 1967 ett riktgivande föredrag om en konservativ och radikal kriminalpolitik i Norden. Hon analyserade kriminalpolitikens trender, lyfte fram kriminologins nyaste forskningsresultat och gestaltade en framtida kriminalpolitik baserad på dessa. ${ }^{13}$ Texten speglade 1960-talets allmänna intellektuella atmosfär, där den rådande kriminal- och den mer omfattande kontrollpolitiken blev föremål för omvärdering: kriminalpolitikens och straffrättens ändringsbehov härleddes från ändringar i samhället och de forskningsresultat som kriminologin påvisat. Till följd av det nya tankesättet uppfattas de olika delområdena av forskning i straffrätt och brottslighet vara i en viktig växelverkan sinsemellan. I rationellt kriminalpolitiskt beslutsfattande bör rätts- och samhällsvetenskaplig forskning omfattande utnyttjas, och även andra vetenskapsområdens (medicinens, 
människo- och naturvetenskapernas) resultat har tilltagande inverkan på det rättsliga beslutsfattandet.

I Finland började man från och med 1960-talet skapa planeringssystem för den offentliga ekonomin och förvaltningen samt i allmänhet förbättra hur forskning utnyttjas i samhällspolitiskt beslutsfattande. Detta framgick genom att ett kostnads-nytto-medvetet tankesätt och ett mångsidigt urval medel omfattades i flera kriminalpolitiska förberedelsehandlingar, som typexempel revisionen av bestämmelserna gällande trafikfylleri år 1975. De lagändringar som förverkligades gällde förbättring av förutsättningarna för trafikövervakning, utvidgande och klargörande av området för straffbarhet samt att det villkorliga straffet och boten skulle bli mer användbara alternativ till det ovillkorliga fängelsestraffet än tidigare. Därtill förenhetligades bestämmelserna beträffande trafikfylleri och placerades i strafflagen i syfte att öka på beteendets förkastlighet. ${ }^{14}$

Genom att på motsvarande sätt utnyttja kriminologi fogade straffrättskommittén, som arbetade under åren 1972-1976, kriminalpolitiken tätt samman med annan samhällspolitik och argumenterade för det straffrättsliga systemets inskränkthet i jämförelse med andra medel för förebyggande och kontroll. Kommittén betonade fortsatt straffsystemets generalpreventiva (allmän laglydnad främjande) verkan, men avvisade dess ensidiga sammankoppling med straffens stränghet. ${ }^{15}$ Med liknande motiveringar förordade regeringens proposition till det första skedet av strafflagens totalrevision att användningen av fängelsestraffet inskränktes till det mest nödvändiga, och att det i ljuset av kriminologisk forskningsdata inte var motiverat att vänta sig att en ringa och gradvis sänkning av straffnivån skulle försvaga straffens generalpreventiva verkan. ${ }^{16}$

Kriminologins och annan forskningsdatas inverkan på stiftandet av lag måste bedömas differentierat. En sådan inverkan kan lätt visas då man i lagberedningshandlingarna direkt stött sig på den empiriska kriminologins forskningsresultat. En mera indirekt inverkan på strafflagstiftningens beredning är vanligare, varigenom forskningsdata ändrar på kriminalpolitiska tankesätt. Då är det betydelsefullt hur mycket tidsenlig, på grundforskning baserad forskningsdata som finns tillgänglig och i vilken mån forskare deltar i lagberedningen eller om utnyttjandet av forskningsdata tryggas i beredningen på annat sätt. I strafflagstiftningens totalrevision som förverkligades under åren 1972-2003 var förutsättningarna för ett dylikt utnyttjande av forskningsresultat för övrigt goda, utom att den inhemska grundforskningen gällande straffrättens teoretiska grunder stärktes för sent med tanke på revisionen.

Allt som allt skedde det sedan slutet av 1960-talet en stor brytning i de kriminalpolitiska tankesätten, till följd av vilken de värdebaserade målsättningar som 
kriminalpolitiken eftersträvade och de kriterier för beslutsfattande som uppställdes för den definierades på nytt, visserligen med begrepp som var bekanta redan från upplysningsfilosofin: mot en rationell och human kriminalpolitik. Enligt en nutida tolkning innebär rationalitet en medvetenhet om påverkan, värden och alternativ. ${ }^{17}$ Att minska på brottsligheten är inte den enda målsättningen, utan man eftersträvar snarare att minska på de kostnader som beror på brottslighet och dess kontroll och att fördela den rättvist mellan olika parter (såsom den offentliga makten och enskilda). Med det straffrättsliga systemet eftersträvas nyttighet, rättvisa och humanitet, varigenom kraven på rättvisa och humanitet konkretiseras av de grundläggande och mänskliga rättigheterna. ${ }^{18}$

Differentiering av de värden och målsättningar som definierar kriminalpolitiken samt diversifiering av de principer och intressen som skall beaktas vid valet av medel har även påverkat de förväntningar som ställs på forskning som skall utnyttjas i lagstiftningsarbetet. Det är förståeligt att det under det rådande statsfinansiella läget förutsätts att kostnads- och andra konsekvenser beaktas mera seriöst och systematiskt än tidigare. ${ }^{19}$ Då kriminalpolitiska medel värderas bör således ännu mera tyngd än tidigare läggas på tillvägagångssätt som är alternativ till straffrätten, varvid preventiva åtgärder och andra påföljdstyper har företräde. För förebyggande av brott i näringsverksamhet eftersöks i allt större mån olika modeller som betonar företags självreglering.

\section{Forskningsdata och val av värderingar: färska lagstiftningsexempel}

Utvidgning av området för forskningsdata och utnyttjande av de modeller dessa data erbjuder, så att kriminalpolitik och strafflagens beredning utövas på rationella grunder, utesluter inte att de slutliga valen av värderingar grundar sig i prövning förenlig med demokratiskt politiskt beslutsfattande. Förutom empiriska forskningsresultat lyfter forskning i bästa fall fram rätts- och moralbaserade värdemässiga utgångspunkter som påverkar beslutsfattande och måttstockar för att sammanfoga dessa. Den analyserar också olika avvägningsalternativ för att uppnå de värderingar och målsättningar som ställs upp samt gör konsekvensbedömningar.

Två färska exempel på reformering av det straffrättsliga påföljdssystemet, där utnyttjandet av empirisk forskningsdata varit centralt, men där motiverbarheten i sista hand varit ett resultat av rättsideologiska eller samhällspolitiska val av värderingar kan nämnas: Betydelsen av farlighetsbedömningar vid verkställande av långtidsfångars straff har ökat (senast genom lag 737/2011), och det finns fortsatt planer på att utöka dem. Bedömningen av om dessa lagändringar är motiverade påverkas väsentligen av hur pålitliga dylika farlighetsbedömningar av fångar är i ljuset av forskningsdata. ${ }^{20}$ Men ännu viktigare är hur sådan individualisering av 
brottspåföljder som strävar efter "ofarliggörande" för samhället betonas, då rättsprinciperna om jämlikhet, proportionalitet och förutsebarhet som tillämpas till fångens fördel fungerar som motvikt.

Mitt andra exempel gäller lagändringen om fångars övervakade frihet på prov (629-630/2013). I lagen stiftades som eventuellt villkor för övervakad frihet på prov och livstidsfånges villkorliga frigivning att denne samtycker till läkemedelsbehandling som dämpar sexualdriften. Då jag i riksdagen hördes om lagförslaget $^{21}$ ansåg jag att dess motiverbarhet förutsätter att samtycket baserar sig på fångens fasta vilja, att dylik läkemedelsbehandling på goda grunder uppskattas förhindra att fången gör sig skyldig till ett nytt allvarligt sexualbrott och att denna målsättning inte är möjlig att uppnå med vård- eller stödåtgärder som på ett lindrigare sätt ingriper $i$ fångens integritet. Som jämförelse hade jag erfarenheten att delta i beredningen av avskaffandet av tvångskastrering vid sexualbrott (1970) som kommitténs ${ }^{22}$ sekreterare, varvid motiveringen var - förutom det inhumana i en sådan tvångsåtgärd - att tvångskastrering inte enligt forskningsdata hade de verkningar som man strävade efter med det.

Betydelsen av val av värderingar har varit särskilt accentuerad vid strafflagstiftningens totalrevision (1972-2003). Dess tyngdpunkt låg ju vid en omvärdering av kriminaliseringar (de värden och intressen som skyddas med straffbestämmelser) och de straffhot som skulle uppställas. Strafflagstiftningens innehåll skulle justeras i enlighet med det ändrade rättsmedvetandet och denna fråga ansågs utgöra en del av ett samhälleligt rättviseproblem. Även riksdagens utskott har varit tvungna att i sina betänkanden och utlåtanden ta ställning till dessa frågor om val av värderingar. I sitt betänkande från år 1990 poängterade lagutskottet $^{23}$ att regleringsbehov som samhälleliga förändringar framkallar då och då måste övervägas, och att enbart en omfattande reform ger möjlighet till en tillräckligt omfattande och konsekvent omvärdering. $\AA$ andra sidan ställde lagutskottet upp målsättningen att strafflagen i upp till årtionden borde kunna fylla sin uppgift med ett skäligt antal mindre ändringar. I synnerhet beträffande bestämmelser om ekonomisk brottslighet har denna målsättning inte varit möjlig att uppnå.

I det nämnda betänkandet av lagutskottet fäster jag uppmärksamheten vid två punkter. För det första bekräftade lagutskottet regeringens linjedragning om att straffen som döms ut för brott som riktar sig mot förmögenhet i medeltal är omotiverat stränga jämfört med vissa straff som döms ut för brott som riktar sig mot liv och hälsa. För det andra var det viktigt för lagutskottet att det i det sista skedet av strafflagstiftningens totalrevision i hela den nya strafflagen görs de ändringar 
som möjligen behövs på grund av såväl de straffskalor som fastställts i revisionens olika skeden som de slutliga lösningarna om strafflagens allmänna del.

Regeringen har inte berett en proposition likt den sistnämnda, fastän detta skulle förutsättas för att slutföra strafflagens totalrevision. En sådan proposition vore nödvändig även för att rätta till att vår, till sitt sakinnehåll från och med dess stiftande till 99-procent förnyade, strafflag inte längre skulle framstå som 1889 års strafflag, utan till sitt författningsnummer skulle vara en strafflag från detta århundrade. ${ }^{24}$ Det bör ställas som mål att vi i vår författningssamling senast under 2020-talet även får en formellt ny strafflag. ${ }^{25}$

\section{Straffrättens konstitutionalisering, europeisering och internationalisering}

De ändringar som skett i rättsutvecklingen sedan 1990-talet - straffrättens konstitutionalisering, europeisering och internationalisering - har ställt nya krav på kriminalpolitisk lagstiftning, på lagskipning och på forskning som stöder dessa. Grunden för straffrättens konstitutionalisering och europeisering är Finlands inträde i Europarådet och dess människorättskonvention (1990), Finlands grundrättighetsreform (1995) och Finlands inträde i Europeiska unionen (1995). Stärkandet av EU:s stadga om de grundläggande rättigheterna och utvidgningen av EU:s straffrättsliga kompetens i och med Lissabonfördraget (2009) har skapat ytterligare utmaningar för vår rättskultur.

I fråga om straffrättens internationalisering har det varit betydelsefullt dels att kriminaliseringar baserade på internationella fördrag (det vill säga s.k. världsbrott) ökat och dels att internationella brottmålsdomstolar gällande den internationella straffrättens kärnbrott grundats. I det senare avseendet är de ad hoctribunaler som FN:s säkerhetsråd grundade i början av 1990-talet för att handlägga de allvarliga kränkningar av humanitär rätt som begåtts i forna Jugoslavien och Rwanda bland de viktigaste, samt att Romstadgan för Internationella brottmålsdomstolen, vilken godkändes år 1998, trädde i kraft år 2002.

De nämnda utvecklingsdragen har även ändrat på straffrättens omfattning på så sätt att den materiella straffrätten och straffprocessrätten har ett tätare ömsesidigt samband än förut. Det är på sitt sätt också fråga om att straffrättens omfattning utvidgats då förvaltningssanktioner med karaktär av straff skall bedömas utgående från likadana principer om rättvis rättegång som egentliga straffpåföljder. ${ }^{26}$ Vidare ökar straffrättsjämförelsens betydelse eftersom den europeiska och internationella straffrätten växelverkar med nationella rättsordningar. Därtill är det viktigt att förstå utländska rättsordningars karaktäristiska drag för att förverk- 
liga internationella samarbetsformer vid brottmål och bedöma behovet att tillnärma strafflagstiftningar.

Den framförda utvecklingen har fört med sig att rättskällornas område väsentligen utvidgats och de tolknings- och avvägningsmetoder som gäller vid rättstilllämpning har blivit mer mångsidiga än förr. Samtidigt har straffrättens allmänna läror och den enhetlighet av systemet som lärorna formar satts på prov av denna mångfald (pluralism) av rätten. Sådan inre följdriktighet (koherens) i straffrättssystemet likt förut går inte att uppnå, utan straffrätten differentieras (fragmenteras) och då den tillämpas framhävs iakttagandet av verksamhetsomgivningen (kontextualiteten). ${ }^{27}$

I praktiken innebär straffrättens konstitutionalisering till exempel att de grundlagsenliga begränsningarna för kriminalisering bedöms utifrån principer utformade av riksdagens grundlagsutskott, såsom de krav som legalitetsprincipen innefattar på att straffbestämmelser skall vara tydligt avgränsade och bestämda. ${ }^{28} \mathrm{I}$ praktiken innebär straffrättens europeisering bland annat att EU-rättens direkta tillämplighet, direkta effekt och tolkningseffekt samt proportionalitetsprincipens betydelse övervägs i brottmål med anknytning till EU-rätt. ${ }^{29}$ Det är möjligt att riksdagen kan komma att överväga tillämpningen av det s.k. nödbromsförfarandet med motiveringen att ett föreslaget direktiv skulle påverka grundläggande aspekter av Finlands rättssystem. ${ }^{30}$

Problem som straffrättens internationalisering i praktiken orsakat är bland annat hur en regleringsskyldighet som enligt internationell rätt skall sättas i kraft nationellt skall infogas i Finlands strafflag utan att dess interna rationalitet kränks. Exempel på detta utgörs av de kriminaliseringsskyldigheter som uppställts i konventioner om förebyggande av terrorism, ${ }^{31}$ till följd av vilka man i Finland bestämde sig för att enhetligt bedöma omfattningen på och gränserna för en sådan "proaktiv straffrätt". ${ }^{32}$

\section{Straffrätten och straffrättsforskning under 2020-talet}

Av tradition har ansetts att straffrätten som ett moraliskt laddat rättsområde förändras $\mathrm{i}$ ett långsammare tempo än andra rättsområden. I enlighet med det lagutskottsbetänkande jag redogjort för ovan, "[bör strafflagen] återspegla de i samhället rådande åsikterna om acceptabelt och förkastligt beteende". ${ }^{33}$ Denna utsaga verkar ge uttryck för motstridiga målsättningar: å ena sidan erkänns en viss kontinuitet i bedömningen av gärningsformernas skadlighet och klandervärdhet; å andra sidan en medvetenhet om att strafflagstiftningen snabbare än tidigare borde kunna uttrycka ändringar i förkastligheten av gärningar skadliga för samhället eller individer. Fortsättningsvis kan antas att de internationella och europeiska re- 
gleringsskyldigheterna fortsätter att växa och proportionellt ökar på ändringarna i strafflagstiftningen.

Det är önskvärt att så mycket som möjligt av systemtänkandet och den interna rationaliteten som strafflagens noggranna beredning innefattar förmås bibehållas då den förestående totalrevisionen av Finlands strafflag slutförs samt vid senare ändringar. Strafflagstiftningen bör utvecklas som en del av en systematisk kriminalpolitik och långsiktigt. Basen för slutliga val av värderingar bör bestå av noggrann rättskälleanalys, konsekvensanalyser och annan forskningsdata. Omotiverade skärpningar av straffrättssystemet bör motverkas med de argument som framförts av forskning, vilka berör bland annat fängelsestraffets relativa ineffektivitet, betydelsen av samhälleliga faktorer och omständighetsfaktorer som bakgrundsfaktorer till brottslighet och straffrättssystemets kraftigt selektiva karaktär - såsom Inkeri Anttila framhävde i den text som blev hennes sista. ${ }^{34}$

Att straffrättsvården, som är i ett fast samband med statssuveräniteten, delvis förflyttats och fortsatt förflyttas utom räckhåll för nationalstaternas direkta beslutsfattande är en utmaning för den straffrättsfilosofiska och kriminalpolitiska forskningen och diskussionen samt för forskningen och diskussionen om grundläggande och mänskliga rättigheter. Straffrättsforskningens kontinuerliga uppgift är att stärka den teoretiska grunden för att i strafflagstiftningen och straffrättskipningen ändamålsenligt kunna beakta den för Finland och andra nordiska länder kännetecknande rationella och humana kriminalpolitiken, människo- och grundrättigheterna samt rättsområdets europeisering och internationalisering. Detta förutsätter att rättsprinciper och intressen, vilka är delvis motstridiga eller i ett spänt förhållande sinsemellan, vägs och balanseras. ${ }^{35}$

Forskningsbehovet blir större av att planmässigheten i EU:s kriminalpolitik stärks, och i och med detta växer behovet att genom rättskomparativ forskning skapa grunder för tillnärmning av straffrättens allmänna del i EU:s medlemsstater. ${ }^{36}$ Den internationella straffrätten är ett särskilt betydande delområde vid forskningen av rättens mångfald och differentiering, eftersom den sammanfogar olika rättsområden (internationell rätt, humanitär rätt, människorättsjuridik och nationell straff- och straffprocessrätt) samt olika verkställighetsmodeller (övernationella, nationella och blandade straffrättssystem). ${ }^{37}$

Straffrättsforskarna i Finland och i andra nordiska länder bör sträva efter att aktivt påverka den internationella diskussionen och beslutsfattandet (skapandet av normer och standarder) utifrån vårt lands och andra likasinnades värdepremisser. Till dessa hör - förutom värden i form av demokrati, mänskliga rättigheter och rättstaten - bl.a. kraven på legitimitet, en relativt låg repressionsnivå och humanitet. Exempel på dylik verksamhet är arbetet av Europeiska Kriminalpolitiska in- 
stitutet (HEUNI), som fungerar i samband med Förenta Nationerna, ${ }^{38}$ och de manifest i Europeisk kriminalpolitik och straffprocessrätt $(2009,2013)$ som en straffrättslig forskargrupp från vår världsdel gjort upp. ${ }^{39}$

De värden av det beskrivna slaget som Finlands kriminalpolitik representerar och dess framgång har fått positiv uppmärksamhet i den internationella diskussionen, ${ }^{40}$ och den har därför varit en innovativ exportprodukt. Från mitt eget influensområde refererar jag till den år 1924 grundade Internationella straffrättsföreningens (AIDP) verksamhet $\mathrm{i}$ fråga om utvecklandet av områdets normer och standarder, senast genom de resolutioner om förebyggande av brottslighet i informationssamhället som godkändes av AIDP:s XIX världskongress i Rio de Janeiro i början av september $2014 .^{41}$

Den straffrättsvetenskapliga forskningen har under de senast årtiondena varit både teoretiskt-metodologiskt och innehållsmässigt mångsidig. Den har på ett gott sätt omfattat läroämnets olika delområden (straffrättens allmänna och särskilda del, straffprocessrätt samt europeisk och internationell straffrätt). I en arbetsmarknadsenkät (2013) uppfattades straffrätten vara bland de 3:e-4:e centralaste läroämnena ${ }^{42}$ Straffrätten har under de senaste årtiondena även varit bland de 3:e-4:e populäraste läroämnena bland författare av magisteravhandlingar vid Helsingfors universitet. Mängden doktorsavhandlingar inom området för straffrätt är bland de största vid Helsingfors fakultet. I Finland har man lyckats engagera de mest begåvade av utexaminerade jurister som lärare och forskare i straffrätt vid universitetet.

Allt som allt anser jag att straffrättsvetenskapens framtid är ljus. Det är även ett nöje att få fortsätta vid min alma mater som en aktiv emeritusprofessor i arbetshandledningsuppgifter och forskningsprojekt.

\section{Noter}

1. Avskedsföreläsning 17.9.2014 (i Porthania vid Helsingfors universitets) med smärre revideringar och tillägg beträffande hänvisningar.

2. Raimo Lahti är jur.dr., pol.mag. och professor i straffrätt (emeritus) vid Helsingfors universitet. E-mail: raimo.lahti@helsinki.fi

3. Paul Enokssons svenska översättning av Beccarias verk utkom 1977 (Casa editrice Italica Stockholm-Roma. Stockholm 1977).

4. Se Raimo Lahti: Inkeri Anttila (1916-2013), In Memoriam. Revue Internationale de Droit Pénal, Vol. 84, 2013/1-2, s. 13-15.

5. Se närmare Raimo Lahti: Elements of Style. Helsinki Law Review 2014/2, s. 313-318.

6. Se Markus Wahlberg: Den finska straffrättsvetenskapens födelse I. Forum Iuris. Helsingfors 2003, s. 48 jämte hänvisningar. 
7. Se Stig Strömholm: Bakgrund och förutsättningar för Cesare Beccarias verk. Svensk Juristtidning 1979, s. 657-662 (661)

8. Beccaria 1977, s. 197.

9. Se Raimo Lahti: Criminal Sanctions in Finland: A System in Transition. Scandinavian Studies in Law 1977, s. 119-157 (122-127) jämte hänvisningar.

10. Lagutskottets betänkande 3/1867 (Nådiga Propositionen N:o 11), s. 508-509.

11. Se utav hans artiklar t.ex. Tapio Lappi-Seppälä: Penal Policies in the Nordic Countries 1960-2010. Journal of Scandinavian Studies in Criminology and Crime Prevention, Vol. 13, Suppl. 1, 2012, s. 85-111.

12. Om utvecklingen se närmare Lahti 1977, s. 127-143 jämte hänvisningar.

13. Inkeri Anttila: Konservativ och radikal kriminalpolitik i Norden. Nordisk Tidsskrift for Kriminalvidenskab (NTfK) 1967, s. 237-251.

14. Se Lahti 1977, s. 143-155.

15. Kommittébetänkande 1976:72. Helsingfors 1977, kap. II.

16. Regeringens proposition (RP) 66/1988 rd, Allmän motivering, kap. 4.4; Detaljmotivering, kap. 1.2.1.1.

17. Se särskilt Inkeri Anttila \& Patrik Törnudd: Kriminologi i kriminalpolitiskt perspektiv. Norstedts. Stockholm 1973, passim.

18. Se Raimo Lahti: On the Reduction and Distribution of the Costs of Crime. OikeustiedeJurisprudentia1972:1 Suomalainen Lakimiesyhdistys), s. 298-313; Lahti: Kriminalvetenskaplig forskning och kriminalpolitik. NTfK 1986, s. 353-362.

19. Se för de färska officiella ställningstagandena angående kriminalpolitik och det straffrättsliga påföljdssystemet i justitieministeriets framtidsöversikt 2014: Ett rättvist, öppet och förtroendebaserat samhälle. Justitieministeriets publikationer 2014.

20. Se senast omfattande om detta P.H. van Kampen \& W. Young (eds.): Prevention of reoffending; Prévention de la récidive. Intersentia. Cambridge-Antwerp-Portland 2014.

21. RP 140/2012 rd.

22. Komittébetänkande 1968: A 11. Helsingfors 1969.

23. Lagutskottets betänkande (LaUB) 6/1990 rd (RP 66/1988 rd), Utskottets överväganden, Allmän motivering.

24. Enligt mina uträkningar är endast 4 av strafflagens, som numera består av 53 kapitel, cirka 650 paragrafer i kraft i sin ursprungliga form (SL 2:6 och 18; SL 18:2-3), och även av dessa är de två först uppräknade bestämmelserna av teknisk natur.

25. Se närmare Jussi Matikkala: Om slutskakning - den finska strafflagsrevisionens sista fas. I verket Pirjo Laitinen (red.): Nordisk workshop för straffrätt 23.-25.3.2007. Rovaniemi 2007, s. 95-105.

26. Se Raimo Lahti: Sanktionsavgifter eller straff. Referat. Förhandlingarna vid Det 39:e nordiska juristmötet i Stockholm 18-19 augusti 2011. Del I. Utgivna av den svenska styrelsen, s. 391-398.

27. Se Raimo Lahti: Towards Internationalization and Europeanization of Criminal Policy and Criminal Justice - Challenges to Comparative Research. I verket Emil W. Pływaczewski (ed.): Current Problems of the Penal Law and Criminology. Wolters Kluwer Polska Sp. 2012, s. 365-379 (376). 
28. Se särskilt Sakari Melander: Kriminalisointiteoria - rangaistavaksi säätämisen oikeudelliset rajoitukset. Suomalainen Lakimiesyhdistys. Helsinki 2008 (Abstract: A Theory of Criminalization - Legal Constraints to Criminal Legislation); Raimo Lahti: De grundläggande rättigheterna och straffrätten. NTfK 1998, s. 295-307.

29. Se närmare från en finsk synvinkel Sakari Melander: EU-rikosoikeus [EU-straffrätt]. Helsinki 2010, kap. V-VI; Raimo Lahti: Harmonisering av den straffrättsliga lagstiftningen och konsekvenser för den nationalle lagstiftningen. Materiella och rättskipningsrelaterade stötestenar. Tidskrift, utgiven av Juridiska Föreningen i Finland 2004, s. 377-385.

30. Artikel 82 punkt 3 i fördraget om Europeiska unionens funktionssätt (2008/C 115/01).

31. Se närmare Mikael Lohse: Terrorismirikoksen valmistelu ja edistäminen. Suomalainen Lakimiesyhdistys. Helsinki 2012 (Sammanfattning: Förberedelse till och främjande av terroristbrott).

32. Genom lag 435/2013 tog man in nya förberedelsekriminaliseringar i strafflagen (SL 21:6a, 25:4a och 31:2a).

33. LaUB 6/1990 rd (RP 66/1988 rd), Utskottets överväganden, Allmän motivering.

34. Inkeri Anttilas tacksägelseadress till European Society of Criminology med anledning av European Criminology Award 2011. Criminology in Europe 2011/3.

35. Se Lahti 2012, s. 375-377.

36. Se närmare André Klip (ed.): Substantive Criminal Law of the European Union. Maklu. Antwerpen-Apeldoom-Portland 2011.

37. Se allmänt Larissa van den Herik \& Carsten Stahn (eds): The Diversification and Fragmentation of International Criminal Law. Martinus Nijhoff Publishers. Leiden-Boston 2012.

38. För FN som en kriminalpolitisk aktör se allmänt Slawomir Marek Redo: Blue Criminology. The power of United Nations ideas to counter crime globally. A monographic study. HEUNI et al. Helsinki 2012.

39. Manifesten står till förfogande i elektronisk form: Manifesto on European Criminal Policy (ZIS 2009, s. 697-747; www.crimpol.eu/manifesto); Manifesto on European Criminal Procedure Law (ZIS 2013, s. 412-446; www.crimpol.eu/manifesto-ii).

40. Se särskilt John Pratt \& Anna Eriksson: Contrasts in Punishment. An explanation of Anglophone excess and Nordic exceptionalism. Routledge. London - New York 2013.

41. Se för resultaten av denna kongress Revue Internationale de Droit Pénal (RIDP), Vol. 85, 2014/3-4. Jag var den ansvariga organisatören för kongressens förberedande kollokvium beträffande internationell straffrätt (i Helsingfors universitet i juni 2013), och dess material har publicerats i RDIP:s band 2014/1-2 och i samma journals elektroniska versions (eRIDP) digitala årgång 2014.

42. Jarkko Tirronen: Oikeustieteellisten tutkintojen kehittäminen ja työmarkkinoiden tarpeet [Utvecklandet av juridiska examina och arbetsmarknadens behov]. Oikeus 2013, s. 194211 (203). 